\title{
Neck Shaft Angle of Non-articulated Femur Bones among Adults in Nepal
}

Anusuya Shrestha ${ }^{1}$, Nirju Ranjit ${ }^{1}$, Rajani Shrestha ${ }^{1}$

${ }^{1}$ Department of Anatomy, Institute of Medicine, Kathmandu, Nepal.

\section{ABSTRACT}

Introduction: The neck-shaft (collo-diaphysial) angle of the human femur bone is an important factor for the hip stability and normal walking. It has been described that neck shaft normally ranges from the angle of $115^{\circ}$ to $140^{\circ}$. The main objective of the study is to evaluate the neck shaft angle of the non-articulated adult Nepalese femur bones. Methods: Altogether 100 nonarticulated adult human femur bones with 50 right and 50 left were taken from a renowned anatomy laboratory. The femora were of unknown sex, age and race. Use of simple protector was used to measure the neck-shaft angle. Both the anterior and posterior views were observed and 200 measurements were recorded. Results: The mean value of neck shaft angle was $127.71^{0}$ with standard deviation of $5.78^{\circ}$. The mean angle of $128.46^{\circ}$ and $126.97^{\circ}$ with the respective standard deviation of $5.83^{\circ}$ and $5.66^{\circ}$ were observed with respect to the right and left adult femur bones. Conclusion: The neck shaft angle of non-articulated adult femur bone of Nepalese people had no remarkable dissimilarity with the angles observed in the studies conducted in the neighboring countries. Neither was there any significant difference between the neck-shaft angle of right and left adult femur bones of the Nepalese.

Keywords: collo-diaphysial angle; femoral neck; orthopaedics.

\section{INTRODUCTION}

The angle formed by the longitudinal axis of the neck and the longitudinal axis of the shaft of femur bone is termed as neck shaft or collodiaphysial angle. This angle varies with age, sex, race, dominant and non-dominant leg or development of femur. The neck shaft generally ranges from the angle of $115^{\circ}$ to $140^{\circ}$ at an average of $126^{0}$ in adults ${ }^{1}$. The proximal femur acts as a brace, and its biomechanical properties depend on the width and length of the femoral neck. It also helps the limbs to swing clear of pelvis. Different aspects of clinical disease conditions and fracture, congenital anomalies and changes in osteoporosis as well as medico-legal cases can be understood by the study of femur bone ${ }^{2}$. Femur bone has almost cylindrical shaft and a proximal rounded articular head projecting medially from its neck. The femoral neck is about $5 \mathrm{~cm}$ long and connects the head to shaft at about an angle of $135^{\circ}$. The mobility of hip joints is facilitated by the angle and it allows the obliquity of the femur within the thigh, which helps the knees to be adjacent and inferior to trunk. It enables to swing clear of the pelvis ${ }^{3}$.

Correspondence: Rajani Shrestha, Department of Anatomy, Institute of Medicine, Kathmandu, Nepal. Email: rajanishresthao15@gmail.com 
Numerous people are affected from fractures of the bone, especially in an elderly age. The lifetime risk of osteoporosis related fractures in the hip, spine and wrist is considered to be $30-40 \%$ in women and $13-20 \%$ in $\mathrm{men}^{4}$. As humans grow from childhood to adulthood, the neck shaft angle decreases significantly because of the changes in body portion and adaptation of hip joint to vertical posture ${ }^{5}$. Hip axis length, femoral neck axis length, neck shaft angle and femoral neck width collectively influence the risk of fracture especially in women apart from bone mineral density. A study shows that UK men have an average femoral neck shaft angle of $130^{\circ}$ with standard deviation of $3.3^{\circ}$, ranging from $121^{0}$ to $138^{\circ}$, similarly the average is $128^{\circ}$ with standard deviation of 1.7 and the range is $119^{0}$ to $137^{0}$ for women ${ }^{6}$. However, studies carried out among Pakistani ${ }^{7}$ and Indian $^{8}$ populations show different dimensions of neck shaft than of the UK population. Therefore, the present study aims to evaluate the neck shaft angle of the non-articulated adult Nepalese femur bones with an intent to provide more knowledge on the femoral geometry.

\section{METHODS}

This was a descriptive study conducted in a renowned Human Anatomy Laboratory with permission from the ethical committee of the institute. A sample of 100 unpaired nonarticulated dry adult femur bones in complete forms were used in this study. The measurements of neck-shaft angle of all bones were taken with both anterior and posterior views and altogether 200 measurements were recorded. Instruments like linear metallic scale, ordinary measuring tape and simple protractor were used to measure the angles. The proximal end of the bones was placed in horizontal planes with accurate positions, and their anterior as well as posterior views were photographed correctly. The images were stored and the measurements of the neck-shaft angles of both anterior and posterior views were listed manually by adopting the standardized technique.

\section{RESULTS}

While considering the measurements from both anterior and posterior views, the mean neck-shaft angle of right femur bone was $128.46^{0}$ with standard deviation of $5.83^{\circ}$ whereas the mean angle of left femur bone was less with $126.97^{\circ}$ along with standard deviation of $5.66^{\circ}$, but no significant difference was observed ( $p$-value $>0.05$ ). The mean of overall measurement was $127.71^{0}$ with standard deviation $5.78^{\circ}$.

Regarding anterior measurement, the mean neck-shaft angle of right femur bone was $129.92^{0}$ with standard deviation of $6.12^{0}$. Likewise the mean neck-shaft angle of left femur bone with anterior view was $127.36^{\circ}$ with standard deviation of $5.59^{\circ}$. This observed difference was found statistically significant ( $p$-value $<0.050$ ).

Similarly, in this study the mean neck angle of the right femur bone was $127^{0}$ with standard deviation of $5.18^{0}$ while observing posterior view and for left femur bone the mean neckshaft angle was $126.58^{\circ}$ with standard deviation of $2.76^{0}$ of the same view. No significance difference was observed for the measurement ( $p$-value $>0.05$ ). 
Table 1: The neck-shaft angle of non-articulated dry adult femur bones with both anterior and posterior views.

\begin{tabular}{|c|ccccc|}
\hline \multicolumn{2}{|c|}{ Parameters (in degrees) } & Mean $( \pm$ SD $)$ & Minimum & Maximum & p-value \\
\hline $\begin{array}{c}\text { Neck-shaft } \\
\text { angle }\end{array}$ & Right $(\mathbf{n}=\mathbf{1 0 0})$ & $\mathbf{1 2 8 . 4 6}( \pm \mathbf{5 . 8 3})$ & 115 & 142 & $\mathbf{0 . 0 6 8 2}$ \\
& Left $(\mathbf{n}=\mathbf{1 0 0})$ & $\mathbf{1 2 6 . 9 7}( \pm \mathbf{5 . 6 6})$ & 110 & 139 & \\
& Total $(\mathbf{n}=\mathbf{2 0 0})$ & $\mathbf{1 2 7 . 7 1}( \pm \mathbf{5 . 7 8})$ & 110 & 142 & \\
\hline
\end{tabular}

Table 2: The neck-shaft angle of non-articulated dry adult femur bones with anterior views

\begin{tabular}{|c|ccccc|}
\hline \multicolumn{2}{|c}{ Parameters $($ in degrees $)$} & Mean $( \pm$ SD $)$ & Minimum & Maximum & p-value \\
\hline $\begin{array}{c}\text { Neck-shaft } \\
\text { angle }\end{array}$ & Right $(\mathbf{n}=\mathbf{5 0})$ & $\mathbf{1 2 9 . 9 2}( \pm \mathbf{6 . 1 2})$ & 115 & 142 & $\mathbf{0 . 0 3 1 4}$ \\
& Left $(\mathbf{n}=\mathbf{5 0})$ & $\mathbf{1 2 7 . 3 6}( \pm 5.59)$ & 118 & 139 & \\
\hline
\end{tabular}

Table 3: The neck-shaft angle of non-articulated dry adult femur bones with posterior views

\begin{tabular}{llllll}
\hline Parameters (in degrees) & Mean $( \pm \mathrm{SD})$ & Minimum & \multicolumn{2}{c}{ Maximum } & \multicolumn{2}{c}{ p-value } \\
\hline $\begin{array}{l}\text { Neck-shaft } \\
\text { angle }\end{array}$ & Right $(\mathrm{n}=50)$ & $127.00( \pm 5.18)$ & 115 & 142 & 0.7022 \\
& Left $(\mathrm{n}=50)$ & $126.58( \pm 5.76)$ & 118 & 139 & \\
\hline
\end{tabular}

\section{DISCUSSION}

In this study, the mean neck-shaft angle of non-articulated bones was observed $127.71^{0}$ with standard deviation of $5.78^{\circ}$, which falls under the range $115^{0}$ to $140^{\circ}$ given by Moore et al. ${ }^{1}$. Almost similar findings have been reported in previous studies in the neighboring countries (Table 4).The results from studies in Pakistan $^{7}$ and India ${ }^{8}$ are coherent with our findings. However, the result from another study in South India ${ }^{9}$ has a little higher value of mean neck-shaft angle, whereas in another study in India $^{10}$ again, the result has been reported lower than that of the present study.

Present study shows no significant difference of neck shaft angle between right and left femur bone as p-value is greater than 0.05 . The angles with right and left femur bones are measured with mean angles $128.46^{\circ}$ and $126.97^{0}$ respectively. These values are low as compared to the mean values of right and left showed by Gujar et al. ${ }^{2}$ which has presented the mean value of $136.6^{\circ}$ of right and $136^{\circ}$ of left respectively. Another study has the similar findings, reporting the angle of $122.5^{\circ}$ to the right and $125.6^{0}$ to the left femur ${ }^{11}$.

Anterior and posterior measurements have also been recorded and analyzed separately in this study. The measurement of right and left neck shaft angle from anterior views shows the mean of $129.92^{\circ}$ and $127.36^{\circ}$. The difference is statistically significant.

Regarding posterior measurements, the mean angle is $127^{\circ}$ and $126.58^{\circ}$, without any significant difference. 


\section{CONCLUSION}

The neck shaft angle of non-articulated adult femur bone of Nepalese people was found similar to that found in the studies conducted in the neighboring countries. There was no significant difference between the neck-shaft angle of right and left adult femur bones of the Nepalese either.

\section{REFERENCES}

1. Moore KL, Dalley AF, Agur AMR. Clinically Oriented Anatomy. USA: Lippincott Williams \& Wilkins; 2013.

2. Gujar S, Vikani S, Parmar J, Bondre KV. A Correlation Between Femoral Neck Shaft Angle to Femoral Neck Length. Int $J$ Biomed \& Adv Res 2013; 4(5): 295-298.

3. Williams PL, Warwick R, Dyson M, Bannister LH. Gray's Anatomy. USA: Churchill Livingstone; 1989.

4. Tian PT, Chen Y, Leow WK, Hsu W, Howe TS, Png MA. Computing NeckShaft Angle of Femur for X-Ray Fracture Detection. In: Petkov N, Westenberg, editors. Computer Analysis of Images and Patterns. CAIP 2003: Proceedings of 10th International Conference; 2003 August 25-27; Groningen, The Netherlands. Berlin: Springer; 2003. p. 82-89.

5. Bulandra, AM, Gielecki JS, Leciejewska I, Karaszewski P. Digital-Image Analysis of the Femoral Shaft/Neck Angle in Human Fetuses. Folia Morphol 2003; 62(4): 415-17.

6. Tuck SP, Rawlings DJ, Scane AC, Pande I, Summers GD, Woolf AD, Francis RM. Femoral Neck Shaft Angle in Men with
Fragility Fractures. J Osteoporosis 2011 ; Article ID 903276. Available from: http:// dx.doi.org/10.4061/2011/903726

7. Ali L, Uddin S, Akhtar KM. 2003. Neck Shaft Angle of Femur in Paksitani Population. The Professional 2003; 10(1): 19-22.

8. Ravichandran D, Muthukumaravel N, Jaikumar R, Das H, Rajendran M. Proximal Femoral Geometry in Indians and its Clinical Applications. J Anat Soc Ind 2011; 60(1): 6-12.

9. Khan SM, Saheb SK. Study on Neck Shaft Angle and Femoral Length of South Indian Femurs. Int J Anat Res 2014; 2(4): 633-35.

10. Siwach RC, Dahiya S. Anthropometric Study of Proximal Femur Geometry and its Clinical Application. Indian J Orthop 2003; 37(4): 247-251.

11. Silva VJD, Oda JY, Santana DMG. Anatomical Aspects of the Proximal Femur of Adult Brazilians. Int J Morph 2003; 21(4): 303-308. 